\title{
Representações de masculinidades latentes em aulas de física do ensino médio*
}

Josimeire M. Julio

Universidade Federal de Minas Gerais

Escola Estadual Reny de Souza Lima

\section{Arnaldo M. Vaz}

Universidade Federal de Minas Gerais, Colégio Técnico

Programa de Pós-Graduação em Educação

O público masculino tem figurado em desvantagem em estatísticas educacionais em relação ao público feminino. Ora protagoniza violência - como autor ou vítima -, ora é levado à evasão, sobretudo do ensino médio. Nesse quadro, são apontadas falhas na educação masculina no contexto e ambiente escolar e destacados os modelos de masculinidade que permeiam o universo dos rapazes (Carvalho, 2001; Connell, 1995; Julio, 2007; Julio \& Vaz, 2008).

Connell (1995) define masculinidade como uma posição nas relações de gênero que influencia as

\footnotetext{
* Versão estendida de trabalho apresentado na $31^{\text {a }}$ Reunião Anual da ANPEd - Grupo de Trabalho de Sociologia da Educação - realizada de 16 a 20 de outubro de 2008 em Caxambu-MG. Elaborada com base nos resultados da dissertação de mestrado em educação Rapazes em situação de investigação: microanálise etnográfica de aulas de Física, orientada por Arnaldo M. Vaz, defendida junto ao Programa de Pós-Graduação em Educação da Universidade Federal de Minas Gerais em 2007.

Agradecemos aos alunos que participaram desta investigação, aos pais e responsáveis que autorizaram essa participação, e a Marlene Machado Zica Vianna pelo trabalho de revisão.
}

práticas e a forma como o sujeito se relaciona com experiências físicas, pessoais e culturais. Portanto, diferentes masculinidades podem se manifestar inclusive em um mesmo indivíduo. Além de múltiplas, as masculinidades são mutáveis e definem-se de maneiras diferentes em grupos diferentes.

O processo de construção e internalização das masculinidades se estabelece, desde a infância, por meio da família, da sociedade e da mídia, sendo reforçado nas histórias e brincadeiras infantis masculinas. Tudo isso desperta nos meninos a necessidade de emancipação através da descoberta, investigação, exploração e dominação do mundo (Blakemore \& Centers, 2005; Statham ${ }^{1}$ apud Giddens, 2005).

Esses e outros fatores mais complexos da organização social têm reflexos diretos na escola. Para Weaver-Hightower (2003), eles evidenciam privilégios masculinos e colocam meninos e rapazes no topo das posições de desempenho, especialmente em disciplinas escolares de alto prestígio, como ciências

${ }^{1}$ STATHAM, June. Daughters and sons: experiences of nonsexist childraising. Oxford: Basil Blackwell, 1986. 
naturais, ciência da computação e matemática avançada. Note-se que "no ensino secundário, as mulheres tendem a ficar invisíveis para a maioria dos livros de ciências e de matemática, eternizando a visão de que essas são disciplinas masculinas” (Giddens, 2005, p. 415, grifo do original). O conhecimento científico tido como um conhecimento hegemônico na cultura ocidental - não raro é associado a características masculinas, visão dominante da divisão sexual (Bourdieu, 1995; Chassot, 2003; Donini, 2001).

Há que se destacar que rotinas e normas de trabalho escolar passivas e recolhidas incomodam muitos rapazes, seja por não atenderem seus interesses, seja por mobilizarem disposições e atitudes que eles consideram femininas (Giddens, 2005; Rocha \& Ferreira, 2002). Isso influencia a maneira como eles percebem a escola e a ela se dedicam. Contudo, cada área ou disciplina escolar exerce seu próprio apelo. A física está entre as disciplinas de alto prestígio, pois é icônica de um ideal de racionalidade muito valorizado na cultura ocidental. Como ciência, ela ainda hoje reproduz padrões de masculinidade nos quais se fundamentou por longos anos (Chassot, 2003; Donini, 2001).

O objetivo deste trabalho é caracterizar aspectos latentes de masculinidades dos rapazes que trazem implicações para a aprendizagem individual e coletiva de alunos e alunas de ensino médio. O contexto do estudo são aulas de física, nas quais uma turma realiza atividades abertas que exigem autonomia; tomadas de decisão; colaboração entre pares; estabelecimento de um sistema de trabalho.

Nesse contexto, pretende-se desvendar o que facilita a ação ou promove uma atitude ativa dos rapazes no que se refere à própria física e no que se refere às tarefas escolares. O estudo desses aspectos visa estabelecer uma articulação com seus interesses pessoais, de modo que contribua para a constituição de um paralelo entre o ensino de física, o papel da escola e a capacidade de diálogo de cada uma dessas dimensões com os rapazes. Desse modo, pretende-se caracterizar, por meio dessa disciplina, aspectos de situações de aprendizagem que podem ser associados a fatores potenciais de sucesso e fracasso escolar mas- culino. As representações de masculinidade de Connell (1995) mostraram-se adequadas a esses propósitos por oferecerem um diálogo com pesquisas semelhantes no Brasil (Brito, 2006; Cruz \& Carvalho, 2006; Daligna, 2005; Julio, 2007; Julio \& Vaz, 2008; Souza, 2006).

\section{As pesquisas de gênero centradas nos meninos e rapazes}

A inversão das desigualdades de gênero na educação a partir dos anos de 1990 em favor das meninas foi considerada uma conquista feminista. Essa inversão tem sido motivo de inquietação não só no Brasil mas também nos países industrializados do primeiro mundo. A maior preocupação com relação a esse problema - principalmente na Grã-Bretanha, nos Estados Unidos e na Austrália - é a de que fatores sociais mais críticos como violência, desemprego, drogas e monoparentalidade estejam associados a ele (Carvalho, 2004, 2003; Giddens, 2005; Louro, 1992; Martino \& Meyenn, 2001). É de se constatar que os rapazes figuram progressivamente em desvantagem nas estatísticas educacionais. Eles são protagonistas de violência, tanto como autores quanto como vítimas, e abandonam a escola sobretudo no ensino médio.

Essas são manifestações de masculinidade de um conjunto significativo de rapazes. Um conjunto que está presente em todos os setores da sociedade, mas agrega principalmente aqueles pertencentes a grupos étnicos e socioeconômicos tradicionalmente marginalizados (cf. Carvalho, 2004), uma situação que mina o projeto de universalização do ensino médio em seu propósito de diminuir desigualdades sociais. O fracasso escolar desses rapazes - em especial - muitas vezes os leva a criar aversão à escola e a tudo que a ela se associe, como conhecimento, estudo, disciplina, hierarquia. Sentindo-se inadaptados e ineptos, têm necessidade de afrontar a sociedade organizada sobre esses pilares e o fazem pela transgressão a suas normas - no limite, pela violência e pelo crime.

Trata-se de uma questão complexa e polêmica. Os grupos étnicos e socioeconômicos tradicionalmente marginalizados estão mais sujeitos à repetência e à 
evasão escolar. Nesse caso, as desigualdades de gênero são influenciadas pelas desigualdades de classe. Para Ajello (2001),

ignorar o fato de que existe uma quota regular de rapazes que abandonam precocemente a escola significa, com efeito, não se dar conta da dificuldade com que esta estrutura lida com uma parte de sua população-alvo. Tal dificuldade poderá indicar, ainda, uma mais geral incapacidade da estrutura para estabelecer um diálogo autêntico com os seus utentes. (Ajello, 2001)

Assim, há uma crescente demanda para que a pesquisa acadêmica volte a atenção para a diversidade que permeia o desenvolvimento afetivo, social e relacional de homens e mulheres na escola, de maneira especial para a produção de conhecimento sobre os problemas masculinos (Rocha \& Ferreira, 2002). Entretanto, no Brasil, a produção de conhecimento acadêmico no campo dos estudos de gênero em educação ainda é muito incipiente, os trabalhos são pouco consistentes e, no que diz respeito ao fracasso escolar masculino, apresentam informações controversas, muitas vezes baseadas no senso comum (Rosemberg, 2001a, 2001b).

É preciso, portanto, recorrer à literatura internacional para ter um panorama das pesquisas centradas em meninos e rapazes. Embora a discussão seja ampla, a área de ensino de ciências não é contemplada. Em contrapartida, os principais aspectos dessas pesquisas são apresentados em uma revisão de literatura publicada por Weaver-Hightower (2003), que aponta sete razões por que elas voltaram o olhar para os meninos e classifica-as em categorias de acordo com sua abordagem. A seguir, expõem-se as principais contribuições dessas pesquisas.

O primeiro grande motivo é o destaque em nível internacional dado pela grande mídia às desvantagens masculinas no sistema educacional. As notícias pautam-se pelas pontuações nos testes padronizados de leitura, pelos indicadores de evasão, pela indisciplina e pelo fracasso escolar, evidenciando que o desempenho das meninas vem superando progressivamente o dos meninos.
O segundo maior estímulo é o trabalho bemsucedido em torno das teorias feministas no decorrer dos anos de 1970, 1980 e 1990, investigando como o gênero influenciava a vida das mulheres, o que abriu espaço para o questionamento sobre os papéis masculinos (Connell, 2000). A partir daí, diversas questões sociais mostraram-se passíveis de exame e intervenção. Entre essas questões estão relações familiares, sociais, econômicas e aspectos físicos da vida masculina associados ao trabalho, aos distúrbios emocionais, à saúde, ao divórcio e às disputas de custódia, à imagem do corpo e à violência, entre muitas outras. A literatura sobre meninos e rapazes constituiu-se com base nas críticas feministas que a precederam. O terceiro fator de estímulo às investigações centradas nos meninos e rapazes foi a formulação de indicadores de igualdade de gênero em educação. Ironicamente, esses são indicadores originários do feminismo que passaram a ser utilizados para mostrar a desvantagem masculina.

O quarto norteador dessa área de pesquisa é o crescimento das reformas educacionais neoliberais e a ampliação dos direitos das mulheres. Essas reformas, promovidas em função desses novos direitos, criaram uma aversão em larga escala que tendia a desafiar, de forma velada, as vitórias feministas. O quinto catalisador foi a oposição geral às políticas de inclusão que explicitamente deixaram as meninas em grande vantagem em relação aos meninos. Violentos ataques ao feminismo aqueceram o debate sobre a necessidade de modificar a natureza feminina da escolarização.

A sexta causa foram as mudanças na economia e na força de trabalho, com o aumento dos setores que valorizam trabalhos tradicionalmente realizados pelas mulheres. Além disso, passou-se a apreciar nas empresas características associadas às mulheres, como modos de interação em grupo com perfis mais colaborativos, em detrimento dos modos de interação mais agressivos e competitivos. O sétimo ímpeto para o foco das pesquisas nos meninos e rapazes foi a influência dos pais, pois a crise de masculinidade e o pânico em que ela resulta não só interferem na vida dos meninos e rapazes como na vida de seus pais e de suas famílias. 
As pesquisas que se originaram desses fatores foram classificadas por Weaver-Hightower (2003) em quatro categorias de literatura: baseada em retórica popular; orientada teoricamente; dirigida pela prática; resultante de reações feministas e pró-feministas.

A literatura baseada em retórica popular toma como motivação o pânico moral, a crise social e o fracasso acadêmico dos meninos, apelando para explicações fundamentadas no determinismo biológico. Biddulph (2002), Pollack (1998), Sommers (2000), representantes dessa literatura, advogam em favor de diferenças sexuais biológicas inatas, como a predisposição para a violência e a agressão, no caso dos meninos. Esses trabalhos normalmente são destaques em manchetes de jornais e revistas de grande circulação e amplamente divulgados pela grande mídia.

A literatura de orientação teórica apresenta a contribuição mais relevante e consistente entre os trabalhos sobre a questão de gênero centrados nos rapazes - por exemplo, pela proposta de metodologias para investigar essa questão. Os autores nela engajados pautam-se pelo conceito de masculinidade elaborado por Connell (1995). Para ele a masculinidade é uma posição nas relações de gênero que influencia as práticas e a forma como o sujeito se relaciona com suas experiências físicas, pessoais e culturais. As masculinidades são múltiplas e mutáveis e definidas de maneiras diferentes em grupos diferentes. Citem-se Connell (1995), Crotty (2001), Mac an Ghaill (1994) e Willis (1977) como autores pioneiros e representativos dessa linha teórica.

Weaver-Hightower (2003) apresenta quatro críticas a essa corrente. A primeira é a de que os trabalhos são centrados em rapazes problemáticos ou destrutivos e nos atletas; os alunos comuns não recebem atenção. Em segundo lugar, essa corrente despreza os aspectos acadêmicos da escolarização e opta por examinar o impacto das diferentes masculinidades na aprendizagem, tomando como parâmetro os processos sociais externos em detrimento do currículo e da cognição. Investiga-se, por exemplo, de que maneira os alunos se relacionam ou definem suas preferências por aprender inglês ou artes. Em terceiro lugar, essa corrente de pesquisa falha em teorizar adequadamente as práticas que defende, porque não tem compromisso com a proposição de práticas baseadas nessas teorias. Por último, falha em dar sentido às particularidades que envolvem pais, professores, os próprios garotos e tende a reforçar posições antifeministas.

A literatura dirigida pela prática pretende resolver os problemas acadêmicos e sociais dos rapazes dentro da sala de aula. Ela difere da literatura teoricamente orientada em questões de investigação, resultados e implicações, não havendo qualquer interação entre as duas correntes. O seu foco de atenção está em explicações e soluções individuais, interacionais e pedagógicas que ocorrem na sala de aula. Essa literatura tende a focar no modo como os rapazes poderão superar os ganhos das moças e, por esse motivo, instiga medo em feministas e pró-feministas. Seus trabalhos raramente mencionam o fato de que as iniciativas dos estudos se baseiam em fundos que financiam programas de engajamento dos rapazes. Publicam-se predominantemente relatórios e indicadores de desempenho em testes divulgados pelo governo. Portanto, é preciso levar em consideração não só que os relatórios são vulneráveis à influência política mas também que a validade das questões dos testes é pouco confiável. São representantes dessa linha Bleach (1998), Browne e Fletcher (1995) e Head (1999).

Para Weaver-Hightower (2003), a literatura teórica e a prática têm muito a oferecer uma à outra e aos estudos de gênero. A união dos dois corpora de pesquisa a partir de seus objetivos comuns poderia promover o aumento da igualdade e a produção de masculinidades melhores. A conexão entre a teorização da prática e a aplicação prática da teoria resultaria no aumento de publicações acadêmicas relacionadas à literatura de ambos os campos.

A literatura resultante das reações feministas e pró-feministas se faz de críticas à pesquisa e à educação centrada nos garotos e rapazes. A maior crítica sobre esses trabalhos é a de que eles não identificam quais são esses indivíduos. Outro ponto de questionamento é a adequação dos indicadores normalmente utilizados para estabelecer as necessidades da sua 
educação. Por exemplo: diferenças de pontuação identificadas no desempenho em testes, particularmente de leitura e alfabetização. Os críticos apontam falhas na elaboração desses testes e grandes imprecisões em seus resultados. Assim, defendem que os argumentos fundamentados nesses dados para demonstrar carências educacionais específicas do público masculino não devem ser aceitos de maneira acrítica. Destacam-se, a seguir, três evidências de que os dados pautados em resultados de testes usados para justificar maior atenção a garotos e rapazes são inadequados.

As diferenças de desempenho nos testes podem ser pequenas ou insignificantes. Em segundo lugar, fatores mais complexos, como raça, escolas urbanas versus escolas rurais e posição socioeconômica tornam insuficiente a comparação simples e direta entre meninos e meninas. Esses pesquisadores e essas pesquisadoras destacam que a pontuação relativamente baixa dos meninos reflete grandes diferenças de pontuação dentro do mesmo grupo. Ou seja, assim como há meninos com as pontuações mais baixas, há também aqueles que estão bem representados no topo das posições de desempenho. Academicamente, os estudantes alcançam pontuações que evidenciam os privilégios masculinos, colocando-os no topo das posições, sobretudo em disciplinas de alto prestígio, como ciência da computação, matemática avançada e ciências. Em terceiro lugar, os críticos levantam a suspeita de que os testes podem ser manipulados para indicar falsas desvantagens (Yates, 2000). Em geral, a maior falha dos testes na medida da desigualdade de gênero está no fato de não refletirem todas as complexidades envolvidas.

Vários pesquisadores da corrente feminista consideram que as desvantagens dos rapazes ocorrem em consequência de possuírem outras vantagens maiores. Eles podem desprezar a leitura, mas usualmente optam por disciplinas mais racionais e de alto prestígio, como as das áreas tecnológicas; em contrapartida, seu acesso privilegiado aos esportes pode levá-los à independência acadêmica. A expectativa de possuírem um alto nível de conhecimento, um privilégio masculino, dá a eles uma autoconfiança exagerada, o que contribui para que estejam mal preparados ao realizar cursos e exames
(Kimmel, 2000). Desse modo, o desempenho dos rapazes no grupo como um todo é puxado para baixo.

É preciso dar atenção ao fato de que, mesmo com posições melhores de desempenho no sistema educacional, fora da escola as meninas continuam em desvantagem em relação aos meninos e rapazes. Teme-se que políticas voltadas para eles comprometam os avanços conquistados por elas. Caso se proponha adaptar o currículo e as pedagogias aos interesses e preferências dos meninos e rapazes para aumentar seu desempenho em leitura, corre-se o risco de reforçar as preferências estereotipadas desse grupo em detrimento das preferências das meninas. Os principais representantes desses estudos são Epstein et al. (1998) e Lingard e Douglas (1999). No Brasil, contamos com Carvalho (2001, 2003, 2004) e Rosemberg (2001a, 2001b).

Este trabalho orienta-se pelo princípio de que há possibilidade de articular elementos da tradição de pesquisas centradas nos rapazes com o ensino de física. Em particular, percorre-se um caminho que une características das pesquisas de orientação teórica e das de orientação prática com os propósitos do ensino de ciências. Para investigar interações que ocorrem em sala de aula, levam-se em conta as manifestações de masculinidade que ocorrem em uma situação de aprendizagem centrada nos alunos. Nesse contexto, a ação recíproca dos indivíduos do grupo se manifesta em quatro dimensões complementares: a relação dos rapazes do grupo; a relação do grupo com a atividade; a relação do grupo com a física; e a relação do grupo com os outros elementos do contexto, como o professor e os outros grupos.

\section{Desenho metodológico}

Cuidados éticos para a proteção dos estudantes foram aprovados no Comitê de Ética e Pesquisa vinculado ao sistema da Comissão Nacional de Ética em Pesquisa. Alunos, alunas e seus responsáveis autorizaram a participação voluntária no estudo por meio de assinatura de termo de consentimento livre e esclarecido. Os nomes citados são fictícios, não se assemelham àqueles de qualquer participante. 
O delineamento metodológico do estudo se inspirou na etnografia. Taft (1999) considera que um pesquisador que investiga a subcultura de uma escola em sua própria sociedade pode ser comparado a um estranho que inicia um estudo antropológico em uma sociedade tradicional. A aculturação nesse meio transforma o observador em um amigo que conhece a linguagem silenciosa do grupo e a íntima comunicação entre seus membros.

O grupo investigado é uma turma de primeiro ano do ensino médio de uma escola pública federal, observada ao longo de um ano em todas as aulas de física. A íntima comunicação entre seus membros ocorre em torno de diferentes variáveis, entre as quais: a relação dos alunos com o professor, com a atividade, com os colegas de outros grupos e com a física. Nesse contexto, a masculinidade é a linguagem silenciosa desconhecida que se articula com todas essas variáveis em diferentes dimensões. O acompanhamento das aulas permitiu que se traçasse, durante o ano, o perfil de cada estudante. Com base nesses perfis, as interações que ocorreram em sala de aula foram analisadas durante um episódio bem recortado no tempo: uma atividade com início, meio e fim, gravada em áudio e em vídeo ao longo de duas semanas.

O processo de análise dos dados - inspirado no trabalho de um etnógrafo - deu-se com um delineamento de pesquisa do tipo descritiva, com ênfase em descrições detalhadas de aspectos holísticos do funcionamento dos grupos pela observação das aulas. Os resultados obtidos foram descrições analíticas que buscaram retratar o contexto e as interações dos participantes observados. Elas privilegiavam o reconhecimento e a classificação de dimensões complementares da ação recíproca dos indivíduos do grupo com cada situação de aprendizagem.

As descrições deram aporte à nova análise através dos episódios e das sequências de ação tomando como referência: (a) a relação dos indivíduos entre si; (b) a relação do grupo com a atividade; (c) a relação do grupo com a física; (d) e a relação do grupo com os outros elementos do contexto - como o professor e os outros grupos.
Um outro nível de análise evidenciou quatro instâncias do funcionamento dos grupos. A primeira delas enfatiza as relações de poder e a articulação entre os componentes do grupo enquanto organizam seu trabalho. A segunda remete ao modo como o grupo lida com aspectos próprios da atividade, entre eles a necessidade de tomadas de decisão, o desenvolvimento da autonomia, o planejamento da solução do problema. A terceira instância denota a relação do grupo com o objeto de conhecimento da física, com a objetividade, com a investigação do mundo. A quarta representa o posicionamento do grupo perante os outros grupos e o professor.

As informações reveladas levaram à: (i) identificação das características comuns aos rapazes envolvidos na situação de aprendizagem; (ii) caracterização descritiva dos aspectos facilitadores da ação dos rapazes; (iii) caracterização descritiva dos aspectos inibidores da ação dos rapazes; (iv) análise cruzada dos resultados obtidos nas etapas ii e iii para os diversos tipos de situações de aprendizagem segundo dois pontos de vista: o da física e o da atividade. As descrições analíticas produzidas se prestaram ao exame das ações dos rapazes como ações masculinas e de sua manifestação em relação à física e à atividade. Tais ações foram analisadas no quadro teórico das representações de masculinidade de Connell (1995).

\section{A turma acompanhada}

$\mathrm{Na}$ turma acompanhada, perfis individuais se sobressaem, alunos e alunas são agitados e tendem a trabalhar individualmente. Eles mantêm-se centrados em fenômenos da física; elas fazem perguntas que envolvem o esclarecimento ou a compreensão das tarefas de sala de aula e se manifestam pouco em discussões com toda a turma.

As moças tendem a manter-se caladas e atentas durante as exposições do professor, e quando desejam se manifestar levantam o braço e esperam sua vez de falar. Os rapazes são dados a mexer uns com os outros, a fazer algum comentário ou brincadeira sempre que o professor aguarda manifestações individuais da 
turma ou faz uma pausa mais prolongada. Eles também tendem a monopolizar as discussões quando são estimulados por algum desafio, problema ou questão a ser resolvida.

Há alunos e alunas mais introvertidos, que falam baixo e têm dificuldade de se expressar nas discussões em aula. Entretanto, o professor faz questão da participação de todos nas aulas e frequentemente convoca-os, dando-lhes voz. Eles e elas reagem de maneiras diferentes a esses apelos: elas propendem a permanecer caladas, mostrando-se tímidas, nervosas, quando o professor faz alguma pergunta ou as interpela; eles participam mesmo quando estão tímidos.

Nas discussões, o modo de falar das moças é mais calmo e suave; entretanto, demonstram ansiedade no tom de voz. Berta é uma exceção; normalmente enfrenta os colegas e sempre que quer ser ouvida exige atenção - tanto dos colegas como do professor. Os rapazes, na maioria das vezes, atropelam as falas dos colegas e levantam questões, procuram se expressar com segurança, como quem quer convencer o outro de seus argumentos.

Alunos e alunas enquadram-se em quatro perfis. Do primeiro participam rapazes que buscam dominar o espaço da sala de aula, como William, Roger, César e Max. Sempre que têm oportunidade, levantam-se, andam pela sala de aula, brincam e dispersam a atenção dos outros colegas. A tendência do segundo perfil é dominar as discussões sobre física. Leonardo, Jean, George, José, James, César, Berta, Carmen, Matilde, Alessandro compõem esse grupo. O terceiro ajusta-se aos que, quando interpelados pelo professor, dão boas contribuições para a discussão: Roger, Charles, Mário, Gabriel. O quarto perfil mantém-se invisível nas aulas: Lélio, Valentina, Michael, Belita, Nicolau, Caroline, Amélia, Tales, Irene, todos têm postura ativa em seu grupo. Em determinado momento do curso, a interação do professor com esses alunos e alunas era praticamente nula.

\section{A atividade instrumento da microanálise}

Um conjunto de aulas é usado para destacar características identificadas nas interações dos alunos que ocorreram durante um ano de observação. A Atividade das estrelas variáveis ocupa seis delas. Nessa atividade, as tarefas permitem que os alunos vivenciem o processo de descoberta, a busca por evidências que comprovem previsões ou descartem a ocorrência de um fenômeno, a disciplina para realizar medidas, a negociação de expectativas e a organização de um plano de trabalho. O seu objetivo é que eles simulem o trabalho de uma comunidade científica, inclusive através de discussões e comunicação entre pares.

Dezoito slides são entregues a grupos de três ou quatro alunos. Neles há uma legenda que identifica uma região do céu - a mesma em todas as fotos - e a data da foto. Eles devem observar os slides, que foram previamente embaralhados, e descobrir se há algum fenômeno que valha a pena ser estudado. Para identificá-lo, os alunos precisam estabelecer um plano de trabalho, dividir tarefas e negociar expectativas com seus colegas de grupo. Eram nove os grupos fixos organizados pelo professor no primeiro dia de aula do ano (Grupo A - Alessandro, Amélia e César; B - Charles, Gabriel e George; C - Belita, James e Jean; D - Berta, Carmen e Caroline; E - Irene, José e Julios; F - Lélio, Leonardo e Matilde; G - Mário, Max, Michael e Valentina; H - Nicolau, Roger e Tales).

A atividade é aberta a diferentes encaminhamentos, o que suscita análises, negociações e distribuição de funções. Ocasionalmente, o professor convoca todos para uma plenária. Com os depoimentos dos grupos, novas facetas da atividade surgem e novos desafios ou dificuldades precisam ser superados. Além disso, as plenárias permitem que todos partam do mesmo nível para novas tarefas, com as mesmas informações.

\section{Primeira aula}

O professor começa anunciando aos alunos o prazer que sentirão desvendando mistérios ou fazendo descobertas. Ele compara a atividade proposta a um jogo em que, para começar, dados coletados por cientistas deverão ser analisados para avaliar se ali há algum fenômeno que vale a pena ser estudado e dis- 
tribui os pacotes com as fotos. Nos grupos, os alunos abrem os pacotes e começam a analisar as fotos para tentar descobrir do que se trata.

\section{Grupo B}

George, Gabriel e Charles percebem as datas das fotos e as colocam em ordem cronológica. George assenta todas as folhas umas sobre as outras e as passa rapidamente sem notar nada. Gabriel conta e distribui as fotos em quantidades iguais para que cada um fique com uma sequência. Enquanto examinam as fotos a seu modo, levantam a possibilidade de ocorrência de dois tipos de movimento. O grupo trabalha em harmonia, buscando evidências de um fenômeno; logo em seguida, o professor convoca a turma para a primeira plenária.

\section{Grupo D}

Berta começa a atividade comentando com Caroline sobre buracos negros. Ao receber as fotos, Caroline mostra a Carmen e Berta que elas retratam uma determinada região do céu. Percebem que uma estrela se parece com o Mickey. Dividem as folhas entre si e as colocam em ordem cronológica. Na tentativa de descobrir como as fotos foram tiradas, Berta consulta o professor, mas ele responde que não pode revelar. Caroline verifica que a região do céu é a mesma e que a câmera pode ter mudado de posição. Em seguida, esclarece que as colegas devem tomar Mickey como referência e avalia que realmente se trata da mesma região do céu. Berta ainda quer descobrir como as fotos foram tiradas. Ela constata que as posições das estrelas em relação ao Mickey são “exatamente iguais” e que não se movem umas em relação às outras. Quando se empolgam durante a comparação, o professor convoca os grupos para a plenária.

\section{Grupo H}

Tales, Roger e Nicolau formam um grupo mais disperso que os outros, mas mesmo assim dedicam-se à realização da atividade. Nicolau pede que os colegas comecem a trabalhar. Roger tenta distrair Tales e Nicolau, o qual diz que precisam descobrir o fenômeno. Eles percebem um aparente movimento das estrelas, e Nicolau tenta explicar por que esse movimento ocorre, revelando que encontraram um fenômeno e se alvoroçam para chamar o professor, que não os ouve.

Após 15 minutos de trabalho dos grupos, o professor faz uma "chamada geral" e solicita que os seus representantes relatem "O que foi feito na busca pelo fenômeno”. Cada grupo terá sua vez de se pronunciar; devem falar em ordem, criticando as observações dos colegas ou acrescentando informações sem repetir o que os outros já disseram.

José, do grupo E, declara que colocaram as folhas contra a luz para ver se havia diferenças entre as fotos. Berta, do grupo D, conta que dispuseram as fotos na ordem das datas e então as compararam. Leonardo, do grupo $\mathrm{F}$, destaca que as colocaram em ordem e foram comparando uma foto com outra, observando a diferença entre a posição das estrelas, mas "sem nenhuma sequência", e depois fizeram a superposição de fotos.

Alessandro, do Grupo A, faz referência ao fato de que, em algumas datas, há uma rotação para a esquerda. O professor chama a atenção dos alunos dizendo que ainda não é o momento de falar sobre qual fenômeno vale a pena estudar. Em seguida, pergunta se alguém ainda pretende comentar algo que não tenha sido dito. James pede a palavra e menciona que o que está sendo observado se repete ao longo do tempo. O professor afirma que o aluno não acrescentou novidades sobre a busca e ressalta a dificuldade de todos em entender a pergunta a respeito do que fizeram, diz que poderiam ter olhado para o trabalho dos outros grupos. Numa síntese, destaca contribuições em plenária que foram pertinentes: colocar os slides em ordem; superpor alguns deles observando-os contra a luz; tomar uma estrela como referência e estabelecer um modo de comparação entre estrelas. Ele enfatiza o Mickey como uma importante referência espacial e as datas como uma referência temporal.

Uma nova fase do debate em plenária é estabelecida: os alunos devem enumerar agora que possíveis 
fenômenos foram identificados. Há algum fenômeno que valha a pena investigar? Qual fenômeno?

Alguns alunos ficam mais atentos, agitam-se nos grupos, verificam o que ocorre nas fotos, levantam os braços em seguida na intenção de comunicar o que observaram. César diz imediatamente:

- Rotação!

José inicia uma frase e, prontamente, levanta o braço. Berta também levanta o braço, em silêncio. O professor dá voz a um grupo que ainda não havia falado, José desiste, a aluna mantém o braço erguido esperando sua vez. Nos grupos B, C, D e E, alunos consultam as fotos enquanto o grupo faz sua exposição. Logo em seguida, Berta tem sua vez; avisa que traz uma informação sobre fenômeno e está com uma dúvida:

- Por que...

- Qual o fenômeno você acha que... (Reforça o professor)

Ela observou que a distância entre as estrelas não muda. Nesse momento, George tenta interrompê-la e dirige-se ao professor atropelando a fala da colega:

- Mas eu acho...

O professor, atento à aluna, faz um gesto para que George aguarde sua vez e deixe a colega concluir seu raciocínio. Berta diz que a posição das estrelas, umas em relação às outras, não muda (simula um giro com as mãos sobre as fotos, para sinalizar que todas as estrelas se moveram juntas na mesma direção). Na sequência, ela começa a expor sua dúvida e argumenta que, se as fotos não foram tiradas na mesma hora, não há como saber se é porque a Terra gira (expressa essa ideia girando as mãos e o corpo). O professor a interrompe, declara que ela já concluiu a tarefa e reafirma:

- A tarefa é listar agora os fenômenos possíveis de serem investigados.
Os outros grupos não se manifestam, e George tem sua vez de falar. Ele segura em suas mãos slides superpostos; diz que, olhando daquele modo, mirando o Mickey, viu que algumas estrelas se "movem mais, outras voltam para uma direção completamente diferente" e afirma enfaticamente:

- Então eu acho que tem movimento das estrelas!

Gabriel emenda a fala do colega de grupo e diz:

- É! No caso da constelação do Mickey, ela gira sempre no mesmo lugar, sempre ligada no mesmo ponto inicial. A "orelhinha” sempre vai rodar no mesmo lugar (desenha uma circunferência no ar, referindo-se ao movimento das orelhas do Mickey).

O professor chama a atenção para a contradição existente entre as afirmações dos dois colegas e as de Berta. Ela havia acabado de dizer que não existe movimento das estrelas. Alessandro reforça:

- As estrelas estão paradas, o que se movimenta é a Terra.

Novamente o professor chama a atenção para as perguntas “O que vale a pena estudar?” e "Qual o fenômeno?”. Aponta as principais dificuldades dos alunos em dizer o que fizeram na busca pelo fenômeno e solicita enfaticamente que eles respondam às seguintes questões: “Qual o fenômeno?” e não “Por que ele ocorre?”. César consulta os slides, chama o professor, levanta o braço e diz:

- Qual fenômeno foi observado? Foi o movimento da Terra, que eu acho, e das estrelas.

- Você observou o fenômeno da Terra? Você observou o movimento da Terra?

Berta levanta o braço imediatamente.

- Observei, no sentido fotográfico (Fazendo movimento de rotação as mãos). 
O professor volta-se para os outros grupos e pergunta se observaram o movimento da Terra e se há evidências disso nas fotos, obtendo respostas afirmativas de alguns alunos. Ele percebe que Berta continua com o braço levantado, aguardando sua vez. Faz um sinal para que ela aguarde mais um pouco e dá a palavra a Gabriel, que está acenando. Gabriel sugere que estão falando em rotação das estrelas, tomando por base a teoria do movimento de rotação da Terra, e não observando diretamente. O professor pergunta se é possível observar movimento das estrelas nas fotos, os alunos dizem que sim. Ele complementa:

\section{- Em relação ao Mickey?}

Berta e Gabriel dizem que não. O professor pede evidências do que os grupos observaram e, finalmente, volta-se para Berta, que continuava em silêncio com o braço erguido:

\footnotetext{
- O quê que vocês observaram?

- A gente observou o movimento das estrelas em relação à margem do papel... (Fazendo movimentos circulares com as mãos sobre as fotos)

- Em relação à margem do papel!!! (Volta-se para a turma agitando o dedo em riste)

- Em compensação, depois a gente observou que não tem movimento das estrelas em relação a elas.
}

O professor pergunta se o "movimento da Terra" pode ser observado nas fotos. Gabriel diz que é só uma teoria. Ele destaca os enganos dos alunos com relação à observação sobre o movimento das estrelas e estabelece uma nova competição em grupo já nos cinco minutos finais da aula para que tentem novamente identificar um fenômeno.

\section{Grupo B}

Gabriel explica aos colegas que o Mickey gira sempre em torno do mesmo ponto, sempre na mesma posição, e que eles devem tomar as “orelhinhas” como referência para observar as estrelas que lhe estão pró- ximas em cada uma das fotos. Nesse intervalo, Berta grita que uma estrela diminui de tamanho, mas a turma está tão compenetrada que não percebe. George superpõe duas fotos, levanta-as um pouco acima da cabeça e observa-as contra a luz. Charles sugere a George que superponha as orelhas do Mickey para ver se as outras estrelas se movem; Gabriel interpela Charles e diz que as estrelas giram em relação à margem do papel, não umas em relação às outras. Ao mesmo tempo, George chama Gabriel, aponta para uma região das fotos e solicita que ele confirme se há uma estrela que diminui de tamanho. Como Gabriel confirma a mudança de tamanho, George, inquieto, levanta o braço e chama o professor, que está atendendo a um outro grupo e não vê os gestos. Gabriel solta um grito de satisfação e faz um "v" com os dedos acenando rapidamente para a câmera. O professor vai à frente da sala encerrar a aula e não atende ao chamado de George, que agita os dois braços.

\section{Grupo D}

Logo que começam a examinar as fotos, Berta empina-se sobre a carteira de repente, olha para frente, agita-se e exclama em voz alta:

- Uma estrela diminuiu de tamanho! Como assim?!

Carmen pega algumas fotos que estão com Berta e as examina. Ela volta a debruçar-se cuidadosamente sobre as fotos, depois levanta, debruça-se sobre a carteira de Caroline, mostra a estrela que diminuiu e chama o professor, que está do outro lado da sala atendendo a um grupo e não a ouve. Ela o chama mais uma vez, levanta o braço e exclama novamente, sem que ele percebesse seu gesto e a atendesse:

- Ô professor! Eu vi uma estrela que diminui de tamanho!

Nesse momento, Matilde volta-se para ela, que acaba de sentar-se ainda agitada, e as duas conferem a posição da estrela nas fotos. Em seguida, Matilde adverte Berta: 
- Você não podia contar, hein!

Ela chama o professor mais uma vez erguendo mais ainda o braço, volta a conferir as fotos. Berta lamenta que o professor esteja ocupado e não a veja. Em seguida, ele encerra a aula sem que Berta tenha a chance de contar sua descoberta.

\section{Grupo H}

O grupo esboça a tentativa de identificar o fenômeno, mas logo se dispersa e desiste da tarefa.

\section{Segunda aula}

$\mathrm{Na}$ aula seguinte, antes de distribuir as fotos aos grupos, o professor lembra o referencial temporal (datas nas fotos) e o espacial (Mickey); orienta os alunos a buscar mudanças a partir da observação do que não está mudando. Depois anuncia que o jogo vai continuar: todos devem dar sua contribuição para a humanidade, como cientistas. Ele relembra o desafio do final da aula anterior, em que os alunos deveriam encontrar algum fenômeno só olhando as fotos. Conta que pelo menos uma pessoa, um grupo descobriu e manifestou um grande prazer.

- Eureca!

Ele solicita que a pessoa se identifique se quiser. Os alunos entreolham-se em silêncio, e o professor esclarece:

- Alguém, no meio da aula, queria contar que tinha feito uma descoberta. Que é a situação de quem falou: “Eureca”. Venci o desafio!

Os alunos continuam olhando uns para os outros, aguardando que a pessoa se revele. Diante da indefinição dos alunos, o professor declara que, como a descoberta acontecera no dia anterior, o prazer que resultou dela já não era tão intenso. Ele aguarda que alguém se manifeste, mas sem dar qualquer pista de quem seja.
Insiste mais uma vez, perguntando se a pessoa quer contar. George ensaia a iniciativa de dizer alguma coisa, mas Berta ao mesmo tempo levanta o braço e diz:

$$
\begin{aligned}
& \text { - Fui eu... (Meio sem jeito) } \\
& \text { - Fala, Berta! } \\
& \text { - Mas... eu não sei se está certo... }
\end{aligned}
$$

Os colegas fazem um pequeno gracejo com a manha de Berta, e ela conta que, quando colocaram uma foto sobre outra sobrepondo o Mickey, perceberam que algumas estrelas estavam maiores e outras estavam menores. Imediatamente, George leva as mãos ao rosto e dá um tapa na mesa, Gabriel encurva-se sobre a carteira escondendo o rosto e gesticulam em sinal de lamento como se tivessem perdido um gol.

\footnotetext{
- Ai! Que ódio, “véi”! (exclama George, que coloca uma mão sobre a testa e tamborila na carteira com a outra).
}

O professor chama a atenção da turma para a reação do grupo e diz que aquela dor é o outro lado do prazer.

\footnotetext{
- Professor! A gente tinha falado isso, professor! No final da aula (lamenta George, agitando as mãos, visivelmente inconformado).

- Eu também (retruca Berta).
}

O professor lembra que lhes deu a chance, mas que eles não quiseram se identificar. Dito isso, dá continuidade à atividade. George e Gabriel "reclamam” com Berta por ela ter falado primeiro, ela retruca que eles tiveram a oportunidade de falar e não aproveitaram. Nos grupos, os alunos comentam entre si; Irene e José afirmam que também iam falar, pois já haviam percebido. Matilde comenta que viram no final da aula, mas não deu tempo de contar ao professor. Michael comenta que também percebeu, mas achou que não era o fenômeno, para ele o fenômeno era o fato de as estrelas não mudarem de posição.

Na sequência, o professor restabelece a competição e alerta que os alunos ainda precisam indicar quais 
são as estrelas que mudam de tamanho. O prêmio para os descobridores será batizar a estrela com o nome do grupo. Embora a atividade tenha como um dos objetivos a compreensão do fenômeno, eles devem antes identificar as estrelas que serão estudadas. As fotos são novamente distribuídas nos grupos, que prontamente começam a trabalhar.

Dessa vez, trabalham de maneira bastante uniforme, distribuem as fotos entre si e começam a examinálas procurando identificar as estrelas que mudam de tamanho. Em instantes, George chama o professor e mostra que o mesmo ocorrera com uma outra estrela. O professor convoca todos os grupos, conta que eles deverão mostrar quais são as estrelas sem apontá-las, sem pôr o dedo, e entrega a cada um deles uma grade quadriculada de acetato transparente.

No grupo B, George, Gabriel e Charles trabalham de forma integrada, observam as fotos e fazem comentários entre si para verificar se as estrelas identificadas realmente mudam de tamanho. No grupo C, Jean coloca os slides em ordem e em seguida todos começam a procurar as estrelas. O grupo D organiza-se desde o início, procura as estrelas que haviam visto no dia anterior e depois decidem verificar se há estrelas que só aumentam ou que só diminuem.

No grupo $\mathrm{H}$, enquanto Tales coloca as fotos em ordem, Roger brinca com os colegas de outros grupos. Chama a atenção dos componentes de outros grupos (Willian, James, Gabriel) dizendo: "Eu descobri!" Quando se viram, os colegas o veem cobrindo as fotos com o envelope.

- Cobri (coloca o envelope sobre as fotos)! Descobri (retira o envelope)!

Os colegas riem e voltam ao trabalho. Tales acaba de ordenar as fotos e passa a examiná-las contra a luz. Roger toma duas delas em suas mãos e as examina do mesmo modo, coloca uma das fotos sobre a mesa, pega outra e repete o procedimento. Nicolau está um pouco disperso e apenas observa o colega. Em cerca de quatro minutos, Roger joga as fotos sobre a mesa e diz ter a explicação para o fe- nômeno, e Nicolau fica atento ao colega. Para Roger, o fenômeno se deve ao movimento de translação, pois as estrelas diminuem. Nicolau concorda; Roger continua expondo sua teoria e diz que a evidência é que as estrelas grandes quase não diminuem e que as estrelas pequenas diminuem só um pouco. Nicolau pede que o colega conte ao professor, mas ele diz que não vai falar.

- Descobrimos, mas não vamos falar.

Roger chama os colegas de outros grupos (José, Julios) e propõe que desistam, pois eles já descobriram. Quando os colegas olham, ele faz a brincadeira com o envelope novamente: “cobre” e "descobre” as fotos. Nicolau insiste em que ele fale ao professor, ouve mais uma recusa. Assim que o professor passa próximo ao grupo ele o chama e diz que já descobriram. Roger conta que todas as estrelas "pequenininhas" se alteram. Antes que o jovem continue, o professor pergunta:

- Quais?

Nicolau diz que essa tarefa é mais difícil; contudo, o professor determina que primeiro deixem claro quais são as estrelas que mudam de tamanho e retira-se. Roger reclama:

$$
\begin{aligned}
& \text { - Aaah (largando, imediatamente, a foto que segurava } \\
& \text { sobre a mesa)! }
\end{aligned}
$$

Nicolau sugere que peguem um lápis para marcar as estrelas. Do grupo C, James critica a atitude dos colegas por estarem querendo escrever no material que não pertence a eles. Enquanto Tales ainda estuda as fotos, Roger e Nicolau se dispersam.

\section{Discussão}

Houve, entre os rapazes, uma predisposição para o desafio e para a competição. Quando se sentiram estimulados a descobrir algo sobre o qual outros alunos não tinham informação, dispuseram-se a trabalhar. 
No caso do grupo $\mathrm{H}$, destacamos a tendência de Roger em desafiar as regras na sala de aula e em dissuadir os colegas de se concentrar na tarefa, tanto em seu grupo quanto em outros grupos. Roger auxiliou o grupo apenas nas questões que exigiam trabalho intelectual, mas recusou-se a tomar medidas ou fazer anotações. Mesmo quando se mostrou curioso ou intrigado com o fenômeno, agiu durante a atividade como se fosse intocável. Nicolau quis se engajar com a atividade em diversos momentos, mas a influência de Roger o demoveu por várias vezes. Havia entre os dois companheirismo quanto aos gracejos e brincadeiras em classe.

Em plenária, os rapazes se mostraram aguerridos tanto no modo de chamar a atenção do professor quanto na forma de se expressar. A tendência de todos eles era de entrar na discussão antes de fazer algum sinal ou aguardar sua vez. Essas estratégias foram frustradas ao longo da atividade pela dinâmica estabelecida pelo professor em classe - cada pessoa teria apenas uma chance de falar e só teria a palavra novamente se as outras não se manifestassem. Entretanto, eles demonstraram pouca paciência para aguardar a vez de se pronunciarem e, quando não eram atendidos ao primeiro sinal, desistiam de participar em plenária.

Os rapazes, mostrando-se combativos tanto no grupo quanto em plenária, apresentavam suas ideias de forma taxativa, de modo que convencessem ou intimidassem os colegas sem dar a eles a oportunidade de argumentar. A maneira como Roger apresentou a explicação para o fenômeno em seu grupo tirou a oportunidade de Tales e Nicolau discutirem melhor as evidências. Quando se posicionou em plenária quanto ao movimento das estrelas, o grupo B reforçou essa ideia em outros grupos, apesar de as evidências apresentadas por Berta - a colega do grupo D - terem sido referendadas pelo professor. Nesse caso, ele precisou dar mais tempo ao debate sobre evidências observáveis e evidências que se pautavam em impressões pessoais.

Ao descobrirem o fenômeno, tenderam a procurar uma explicação, mesmo quando o professor deixava claro que não deveriam explicar naquele momento. Em alguns casos, os rapazes se furtavam em realizar a tarefa estabelecida para se deterem em explicações ou em observações marginais ao fenômeno, como o fato de que a posição das estrelas mudava em relação à margem do papel. Eles desviavam-se das tarefas estabelecidas pelo professor para conduzir a investigação em torno dos próprios interesses.

\section{Considerações finais}

O objetivo deste estudo foi caracterizar aspectos predominantes na interação de rapazes durante situações de aprendizagem em física. Esses aspectos foram investigados tanto do ponto de vista do perfil individual dos alunos quanto do ponto de vista do funcionamento dos grupos de aprendizagem. Houve predisposições diferentes não só em torno da tarefa a ser realizada como também em torno das interações com os colegas, das interações com o professor e em torno da física.

Pesquisas recentes produzidas no Brasil têm buscado interpretar as diferentes relações de gênero que se estabelecem na sala de aula e na escola (Brito, 2006; Cruz \& Carvalho, 2006; Daligna, 2005; Souza, 2006). Os estudos procuram compreender os significados das interações de gênero, seu papel na construção das identidades de meninos e meninas e as relações de poder que se estabelecem com base nas masculinidades e feminilidades construídas. Eles deixam de lado visões estereotipadas das interações de alunos e alunas na sala de aula em favor de observações mais focadas. Entretanto, são realizados no contexto do ensino fundamental, em que se estabelecem relações sem influência de conteúdos específicos, como no nosso caso.

Este estudo leva em conta que as masculinidades se manifestam nos grupos de alunos não apenas na relação entre eles, mas também em sua relação com as atividades em sala de aula e com a física (Julio, 2007; Julio \& Vaz, 2008). O recurso ao conceito de masculinidade serviu para interpretar as interações predominantes identificadas entre os rapazes, não para categorizá-las. Segundo Swain (2006), as tipologias são inadequadas para representar a masculinidade, que é fluida e dinâmica, isto é, muda conforme o contexto e ao longo do tempo. 
Houve uma nítida predisposição dos grupos para engajarem-se na investigação do fenômeno. Entre os rapazes, a predisposição para o desafio, a possibilidade da descoberta e a competição se manifestaram de diferentes modos em diferentes configurações de masculinidade. As interações pautadas por uma disputa de poder entre os rapazes resultaram em uma agressividade que, quando mal administrada, inibiu o avanço dos grupos. Nos casos em que a competitividade se articulou em torno do planejamento e da organização das tarefas, o trabalho colaborativo foi predominante, os alunos conseguiram articular a curiosidade pelo fenômeno com a condução da investigação. No caso em que Roger manifesta traços da masculinidade voltada para o desafio das regras escolares, havia um estímulo constante para que tanto os alunos do grupo quanto aqueles que pertenciam a outros grupos deixassem de se envolver com a atividade. Mas a realização das tarefas não foi totalmente comprometida graças ao interesse e à curiosidade que o tema e a dinâmica de aula despertaram nos rapazes.

A atividade das estrelas articulou um conjunto de tarefas dinâmicas que demandaram planejamento do trabalho em grupo e estimularam a curiosidade dos alunos em torno da possibilidade de descobrir um fenômeno natural. A curiosidade pelo fenômeno foi explorada de diferentes formas para possibilitar a aquisição de técnicas de observação, descrição, realização de medidas, construção e análise de tabelas e gráficos. A atividade serviu de instrumento para destacar e situar os principais aspectos das interações dos rapazes com as múltiplas dimensões da situação de aprendizagem.

Há aqui evidências de que alguns aspectos de masculinidades que se configuram durante situações de aprendizagem em sala de aula podem trazer implicações para a aprendizagem dos alunos, tanto individual quanto coletivamente. Ainda que se procurasse por um padrão de configuração da interação dos rapazes em sala de aula, encontraram-se diferentes aspectos da articulação dessas masculinidades ao longo da atividade e ao longo do acompanhamento das aulas durante o semestre.
Há que se considerar que alguns perfis de masculinidade permitem ao indivíduo ter bom desempenho individual apesar de desafiar as regras e normas estabelecidas em sala de aula. As masculinidades com esse perfil prejudicam o funcionamento e o desempenho dos grupos de aprendizagem em que o sujeito está inserido. Entretanto, as interações de professores e professoras e as características dinâmicas de uma situação de aprendizagem podem ter o potencial de direcionar essas masculinidades em prol da realização de uma tarefa e do desenvolvimento de alunos e alunas.

Os estudos centrados em meninos e rapazes falham tanto ao propor teorias sem preocupação com sua aplicação prática quanto ao implementar práticas que não levam em conta as teorias de masculinidade. Com relação às pesquisas em educação em ciências, encontramos trabalhos que são pouco representativos para a discussão de gênero a partir das masculinidades e circunscritos à questão da inclusão das meninas nas carreiras científicas. Esses estudos falham quando não abordam como a questão das masculinidades interfere na educação em ciências.

Este estudo procurou, por meio do referencial de masculinidade de Connell (1995), analisar interações que ocorrem em situações de aprendizagem que envolvem trabalho em grupo, tomadas de decisão, autonomia e competição. Essas situações de aprendizagem dizem respeito ao estudo da física, uma disciplina que está entre as de alto prestígio acadêmico e, não raro, é associada ao universo de interesses dos rapazes.

Ironicamente, uma menina de um grupo só de meninas descobriu o fenômeno antes de todos os grupos; ela e suas colegas adotaram as recomendações do professor e seguiram os passos indicados durante a condução da investigação. Ela permitiu que outra colega compartilhasse a descoberta e quis contar a todos o que havia percebido. $\mathrm{O}$ grupo de rapazes que percebeu o fenômeno logo em seguida guardou a descoberta para si e, no dia seguinte, lamentou-se por ter perdido a chance de divulgá-la antes dos outros grupos.

As masculinidades que se apresentaram revelaram que os rapazes podem fracassar mesmo quando mostram preferência ou engajamento em determinadas 
dimensões de uma atividade, e mesmo quando estão confiantes de seu sucesso. $\mathrm{O}$ interesse que privilegia apenas uma parte da situação compromete o desenvolvimento desta como um todo. É preciso encontrar meios que permitam fazer com que os meninos e rapazes se dediquem igualmente a todas as dimensões e tarefas de sua educação e não apenas àquelas que consideram lhes oferecer prestígio ou privilégios particulares.

\section{Referências bibliográficas}

AJELLO, Ana Maria. As diferenças de gênero nos estudos sobre aprendizagem e desenvolvimento. S.l.: Projeto POLITE - Saberes e Liberdade, 2001. Disponível em: <http://www.aie.it/polite/ PORAjello.pdf $>$. Acesso em: 7 abr. 2005.

BIDDULPH, Steve. Criando meninos. São Paulo: Fundamento, 2002.

BLAKEMORE, Judith; CENTERS, Renee. Characteristics of boys' and girls’ toys. Sex Roles, v. 53, n. 9-10, p. 619-633, 2005.

BLEACH, Kevan (Ed.). Raising boys' achievement in schools. London: Trentham Books, 1998.

BOURDIEU, Pierre. Dominação masculina. Educação e Realidade, v. 20, n. 2, p. 133-184, 1995.

BRITO, Rosemeire dos Santos. Intrincada trama de masculinidades e feminilidades: fracasso escolar e meninos. Cadernos de Pesquisa, v. 36, n. 127, p. 129-149, 2006.

BROWNE, Rollo; FLETCHER, Richard (Eds.). Boys in schools: addressing the real issues: behavior, values, and relationships. Sydney: Finch, 1995.

CARVALHO, Marília Pinto. Mau aluno, boa aluna? Como as professoras avaliam meninos e meninas. Estudos Feministas, v. 9, n. 2, p. 554-574, 2001.

. Sucesso e fracasso escolar: uma questão de gênero.

Educação e Pesquisa, v. 29, n. 1, p. 185-193, 2003.

. Quem são os meninos que fracassam na escola?

Cadernos de Pesquisa, v. 34, n. 2, p. 185-193, 2004.

CHASSOT, Attico. A ciência é masculina? São Leopoldo: UNISINOS, 2003.

CONNELL, Robert W. Políticas da masculinidade. Educação $e$ Realidade, v. 2, n. 20, p. 185-206, 1995.

The men and the boys. Berkeley: University of California Press, 2000.
CROTTY, Martin. Making the Australian male: middle-class masculinity, 1870-1920. Melbourne: Melbourne University Press, 2001.

CRUZ, Tânia Mara; CARVALHO, Marília Pinto. Jogos de gênero: o recreio numa escola de ensino fundamental. Cadernos Pagu, s.v., n. 26, p. 113-143, 2006.

DALIGNA, Maria Cláudia. Desempenho escolar e gênero: um estudo com professoras de séries iniciais. In: REUNIÃO ANUAL DA ANPEd, 28., Caxambu, 2005. Anais... Caxambu: ANPEd, 2005. DONINI, Elisabetta. A construção cultural das ciências da natureza. gêneros, personagens e fatos históricos. S.l.: Projeto Polite - Saberes e Liberdade, 2001. Disponível em <http://www. aie.it/polite/PORDonini.pdf>. Acesso em: 7 abr. 2005.

EPSTEIN, Debbie et al. Schoolboy frictions: feminism and "failing” boys. $I n$ : (Eds.). Failing boys? Issues in gender and achievement. Buckingham: Open University Press, 1998. p. 3-18.

GIDDENS, Anthony. Educação. In: . Sociologia. 4. ed. Porto Alegre: Artmed, 2005. p. 394-424.

HEAD, John. Understanding the boys: issues of behavior and achievement. London: Falmer Press, 1999.

JULIO, Josimeire M. Rapazes em situação de investigação: microanálise etnográfica de aulas de Física. Dissertação (Mestrado em Educação) - Faculdade de Educação, Universidade Federal de Minas Gerais, Belo Horizonte, 2007. .; VAZ, Arnaldo M. Representações de masculinidades latentes em aulas de Física do Ensino Médio. In: REUNIÃO ANUAL DAANPED, 31., Caxambu, 2008. Anais... Rio de Janeiro: ANPEd, 2008.

KIMMEL, Michael. What about the boys? What the current debates tell us and don't tell us about boys in school. Wellesley, MA, Center for Research on Women's 6th Annual Gender Equity Conference, Special Report, nov. 2000.

LINGARD, Robert; DOUGLAS, Peter. Men engaging feminisms: pro-feminism, backlashes, and schooling. Buckingham: Open University Press, 1999.

LOURO, Guacira Lopes. Uma leitura da história da educação sob a perspectiva de gênero. Teoria e Educação, s.v., n. 6, p. 53-67, 1992. MAC AN GHAILL, Máirtín. The making of men: masculinities, sexualities, and schooling. Buckingham: Open University Press, 1994.

MARTINO, Wayne; MEYENN, Bob. What about the boys? Issues of masculinity in schools. Buckingham: Open University Press, 2001. 
POLLACK, William. Real boys: rescuing our sons from the myths of boyhood. New York: Random House, 1998.

ROCHA, Cristina; FERREIRA, Manuela. Aprender a ser rapaz entre rapazes e raparigas. Masculinidades em duas escolas $\mathrm{C}+\mathrm{S}$ do Distrito do Porto. Trabalhos de Antropologia e Etnologia, v. 42, n. 1-2, p. 49-68, 2002.

ROSEMBERG, Fúlvia. Caminhos cruzados: educação e gênero na produção acadêmica. Educação e Pesquisa, São Paulo, v. 27, n. 1, p. 47-68, jan./jun. 2001a.

. Educação formal, mulher e gênero no Brasil contemporâneo. Rev. Estud. Fem., v. 9, n. 2, p. 515-540, 2001 b.

SOMMERS, Christina Hoff. The war against boys: how misguided feminism is harming our young men. New York: Simon \& Schuster, 2000.

SOUZA, Erica Renata. Marcadores sociais da diferença e infância: relações de poder no contexto escolar. Cadernos Pagu, s.v., n. 26, p. 169-199, 2006.

SWAIN, Jon. Reflections on patterns of masculinity in school settings. Men and Masculinities, v. 8, n. 3, p. 331-349, 2006.

TAFT, Ron. Ethnographic research methods. In: KEEVES, John; LAKOMSKI, Gabrielle (Eds.). Issues in educational research. Oxford: Elservier Science, 1999. p. 113-120.

WEAVER-HIGHTOWER, Marcus. The "boy turn” in research on gender and education. Review of Educational Research, v. 73, n. 4, p. 471-498, 2003.

WILLIS, Paul. Learning to labor. New York: Columbia University Press, 1977.

YATES, Lyn. The "facts of the case”: Gender equity for boys as a public policy issue. In: LESKO, Nancy (Ed.). Masculinities at school. Thousand Oaks: Sage, 2000. p. 305-322.

JOSIMEIRE M. JULIO, doutora em educação pelo Programa de Pós-Graduação em Educação: conhecimento e inclusão social da Universidade Federal de Minas Gerais (UFMG), é membro do grupo de pesquisa Inovar da UFMG e professora de física da Secretaria Estadual da Educação de Minas Gerais na Escola Estadual Reny de Souza Lima. Realiza pesquisas no campo da educação com ênfase em ensino de física nos temas: atividades investigativas, laboratório escolar, interações em sala de aula, estudos de gênero centrados em masculinidades, grupos de aprendizagem, dinâmica de grupos. Publicações recentes: em coautoria com VAZ, Arnaldo M. Atividades de investigação escolar: análise psicanalítica do engajamento em pequenos grupos (Cadernos de Pesquisa, v. 38, n. 138, 2009, no prelo); Rapazes em situação de investigação: microanálise etnográfica de aulas de física (Dissertação (Mestrado em Educação) - Faculdade de Educação, Universidade Federal de Minas Gerais, 2007); em coautoria com VAZ, Arnaldo M. Grupos de alunos como grupos de trabalho: um estudo sobre atividades de investigação (Revista Brasileira de Pesquisa em Educação em Ciências, v. 7, n. 2, p. 5-24, maio/ago. 2007). Pesquisa em desenvolvimento, com apoio do Conselho Nacional de Desenvolvimento Científico e Tecnológico (CNPq): "Interações masculinas à escola: uma abordagem a partir da física”.E-mail: josimeire@coltec.ufmg.br

ARNALDO M. VAZ, doutor em educação em ciências pela University of Surrey (Inglaterra), é professor do Colégio Técnico e do Programa de Pós-Graduação em Educação: conhecimento e inclusão social da Universidade Federal de Minas Gerais (UFMG), onde é membro do grupo de pesquisa Inovar. Realiza pesquisas no campo da educação, com ênfase nas áreas de: ensino de física (nível médio e educação infantil); atividades didáticas de investigação e laboratório; aprendizagem em grupo; e práticas colaborativas de professores. Publicações recentes: em coautoria com JULIO, Josimeire M. Interacciones entre masculinidades: microanálisis de actividades de investigación escolar en física (Revista Mexicana de Investigación Educativa, v. 14, n. 42, p. 721-745, jul./set. 2009); Reflexões éticas de pesquisadores e professores: empecilhos à prática de colaboração e efeitos da coadjuvação (In: NARDI, R. (Org.). A pesquisa em ensino de ciências no Brasil: alguns recortes. São Paulo: Escrituras, 2007. p. 219-238); em coautoria com MENDES, Regina Rodrigues Lisboa, Environmental education in formal education: revealing teachers' experiences and perspectives using the focus group technique in Brazil (In: LEAL FILHO, W.; LITTLEDYKE, M. (Orgs.). International perspectives in environmental education. v. 16. Frankfurt am Main: Peter Lang, 2004. p. 305-321). Pesquisa em desenvolvimento, com apoio do Conselho Nacional de Desenvolvimento Científico e Tecnológico (CNPq): “Aprendizagem colaborativa e engajamento escolar no âmbito do ensino de ciência”.E-mail: arnaldo@coltec.ufmg.br

Recebido em julho de 2008 Aprovado em abril de 2009 
de a publicações da Gazeta do Norte, jornal que assumiu a missão de educar os montes-clarenses, elegendo a Escola Normal de Montes Claros como referência e inspiração para esse empreendimento. Visando seu propósito educativo e considerando os conteúdos em circulação, o jornal produziu representações positivas da escola e das práticas escolares, colocando a educação como eixo de desenvolvimento e progresso. Tais representações, imbuídas de interesses e significações, não são a realidade, mas integraram o processo de informar e formar a opinião pública e contribuíram para consolidar a Escola Normal e mobilizar ações da população local.

Palavras-chave: imaginário social; representações e práticas; apropriação; imprensa.

The press and the Normal School: representations of progress and civilization in the production of the social imagination - 1918-1938

Taking elements from the history of Montes Claros, in the State of Minas Gerais, Brazil, as reference, we discuss the use of the concepts of representation, appropriation and practice (Chartier, 1990, 2001, 2002) and of social imagination (Baczko, 1985), in the context of cultural history. We make use of reports published in the Gazeta do Norte, a newspaper which adopted the mission of educating the population of Montes Claros, choosing the "Escola Normal" (Normal School) as a reference and inspiration for this undertaking. Taking into consideration its educational purpose and the contents published, this newspaper produced positive representations of the school and its practices, situating education as the axis of development and progress. Such representations, full of interest and meanings, are not reality but integrated the process of informing and forming public opinion and contributed to consolidate the
Normal School and mobilize actions by the local population.

Key words: social imagination; representations and practices; appropriation; press.

Prensa y Escuela Normal: representaciones de progreso y civilización en la producción de un imaginario social

Tomando elementos de la historia de Montes Claros, en el estado de Minas Gerais, como referencia, se discute la utilización de los conceptos de representación, apropiación y práctica (Chartier, 1990, 2001, 2002) y del imaginario social (Baczko, 1985), en el contexto de la historia cultural. Se confiere visibilidad a las publicaciones de la Gazeta do Norte, periódico que asumió la misión de educar a los montes-clarenses, eligiendo a la Escuela Normal de Montes Claros como referencia e inspiración para este emprendimiento. Apuntando su propósito educativo y considerando los contenidos en circulación, el periódico produjo representaciones positivas de la escuela y de las prácticas escolares, colocando la educación como eje del desarrollo y progreso. Tales representaciones, llenas de intereses y significados, no son la realidad, sin embargo integraron el proceso de informar y formar la opinión pública y contribuyeron para consolidar la Escuela Normal y movilizar acciones de la populación local.

Palabras claves: imaginario social; representaciones y prácticas; apropiación; prensa.

Josimeire M. Julio e Arnaldo M. Vaz

Representações de masculinidades latentes em aulas de física do ensino médio

O estudo caracteriza aspectos latentes de masculinidades que trazem implicações para a aprendizagem individual e coletiva em uma turma de ensino médio. Aulas de física de uma turma de primeira série do ensino médio foram acompanhadas ao longo de um ano. A microanálise de uma sequência de seis aulas - gravadas em áudio e em vídeo - envolvendo uma atividade que simula o trabalho de uma comunidade científica caracteriza as interações predominantes entre os rapazes. As masculinidades destacadas mobilizamse em torno do estímulo diante de situações desafiadoras e de competição, da curiosidade pelo fenômeno investigado, do desafio às regras estabelecidas na condução da atividade. Entre as implicações do estudo, destaca-se a necessidade de levar em consideração manifestações de masculinidades que possam comprometer o desenvolvimento das atividades em sala de aula e o funcionamento dos grupos de aprendizagem.

Palavras-chave: representações de masculinidade; ensino de física; atividades investigativas.

Representations of latent masculinity in secondary education classes of Physics

The study characterizes latent aspects of masculinity that present implications for individual and collective learning in a class of secondary education. Physics classes of first year students were observed for one academic year. A microanalysis of a thematic unitrecorded on audio and video - in an activity that simulates the work of a scientific community characterizes the predominant interactions between the boys. Some manifestations of masculinity were predominant among boys in classroom activities that were challenging and competitive and others, in which rules had to be observed. Results suggest the kind of circumstances in which such masculinities might be manifested jeopardizing the development of classroom activities and the dynamics of learning groups. 
Key words: representations of masculinity; teaching of Physics; research activities.

\section{Representaciones de masculinidades latentes en clases de física de la escuela secundaria}

El estudio caracteriza aspectos latentes de masculinidades que traen implicaciones para el aprendizaje individual y colectivo de una clase de la escuela secundaria. Clases de física del primer año de una escuela secundaria fueron acompañadas a lo largo de un año. A microanálisis de una secuencia de seis clasesgravadas en audio y en videoenvolviendo una actividad que simula el trabajo de una comunidad científica, caracteriza las interacciones predominantes entre los jóvenes. Las masculinidades destacadas se movilizan en torno del estímulo frente a situaciones desafiantes y de competición, de la curiosidad por el fenómeno investigado, del desafío a las reglas establecidas en la conducción de la actividad. Entre las implicaciones del estudio, se destaca la necesidad de tener en cuenta las manifestaciones de masculinidades que puedan comprometer el desarrollo de las actividades en la clase y el funcionamiento de los grupos de aprendizaje.

Palabras claves: representaciones de masculinidad; enseñanza de física; actividades investigadoras.

Marisa Vorraber Costa e Mariangela Momo

\section{Sobre a "conveniência” da escola}

O artigo pretende mostrar um novo “uso” para a escola, atrelado à lógica do atual estágio da globalização, em que a cultura ocupa uma posição singularmente importante, entremeando-se na vida social, nos circuitos econômicos e regimes políticos. Recorrendo à teorização de George Yúdice sobre os usos da cultura na era global, são analisados três projetos sociais - Você Apita, Tim Música nas Escolas e Escola Aberta - considerados expressivos da forma como empresas, organizações públicas e iniciativas da sociedade civil se articulam com a cultura e a educação para fazer os mercados globalizados se movimentarem, mas não apenas em seus próprios interesses, embora esses persistam no topo das prioridades. Há indícios de que a “conveniência” da escola ultrapassa o interesse mercantil imediato e se projeta como estratégia direcionada a uma variada gama de propósitos sociopolíticos, econômicos e culturais, entre eles a possibilidade de governar a vida das pessoas, forjando visões de mundo e de sociedade.

Palavras-chave: escola e globalização; escola e cultura; governamento; projetos sociais; biopolítica.

On the "convenience" of school This article aims at showing a new "use" for school that is linked to the logic of the current stage of globalization, in which culture occupies a uniquely important position, interwoven with social life, economic circuits and political regimes. Making use of George Yúdice's theorization about the uses of culture in the global era, three social projects are analyzed - Você Apita, Tim Música nas Escolas and Escola Aberta. These projects are considered expressive of the way in which businesses, public entities and civil society initiatives are articulated with both culture and education in order to make globalized markets move, but not only favouring their own interests, although these remain as top priorities. Evidence exists that the "convenience" of school outweighs the immediate business interest and projects itself as a strategy directed towards a wide range of social-political, economic and cultural purposes. Among them is the possibility of governing people's lives, forging both world and societal views.

Key words: school and globalization; school and culture; government; social projects; bio-politics.

Sobre la "conveniencia" de la escuela El artículo pretende mostrar un nuevo “uso" para la escuela, vinculado a la lógica de la etapa actual de la globalización en la que la cultura ocupa una posición singularmente importante, entrelazándose en la vida social, en los circuitos económicos y en los regímenes políticos. Recurriendo a la teorización de George Yúdice sobre los usos de la cultura en la era global, se analizan tres proyectos sociales Você Apita, Tim Música nas Escolas y Escola Aberta - considerados expresivos de la forma como empresas, organizaciones públicas e iniciativas de la sociedad civil se articulan con la cultura y con la educación para hacer con que los mercados globalizados se muevan, pero no sólo en sus propios intereses, aunque ellos persistan en la cima de las prioridades. Hay indicios de que la "conveniencia" de la escuela sobrepasa el interés mercantil inmediato, y se proyecta como estrategia dirigida hacia una variada gama de propósitos socio-politicos, económicos y culturales. Entre ellos, la posibilidad de gobernar la vida de las personas, forjando visiones de mundo y de sociedad.

Palabras claves: escuela y globalización; escuela y cultura; gobierno; proyectos sociales; biopolítica.

Ana Lúcia Felix dos Santos e Janete Lins de Azevedo

A pós-graduação no Brasil, a pesquisa em educação e os estudos sobre a política educacional: os contornos da constituição de um campo acadêmico

Este artigo problematiza especificidades que cercam o campo acadêmico da 